\title{
Epidemiological Investigations on Cystic Echinococcosis in North-West (Sidi Kacem Province) Morocco: Infection in Ruminants
}

\author{
Ikhlass El Berbri, ${ }^{1}$ Anne Françoise Petavy, ${ }^{2}$ Gerald Umhang, ${ }^{3}$ Mohammed Bouslikhane, ${ }^{1}$ \\ Ouafaa Fassi Fihri, ${ }^{1}$ Franck Boué, ${ }^{3}$ and Allal Dakkak ${ }^{1}$ \\ ${ }^{1}$ Department of Pathology and Veterinary Public Health, Institute of Agronomy Veterinary Medicine Hassan II, BP 6202, \\ Rabat-Instituts, Rabat, Morocco \\ ${ }^{2}$ Université Claude Bernard de Lyon, 43 Boulevard du 11 Novembre 1918, 69100 Villeurbanne, France \\ ${ }^{3}$ Agence Nationale de Sécurité Sanitaire de l'Alimentation, de l'Environnement et du Travail, \\ Laboratoire de la Rage et de la Faune Sauvage, BP 40009, Malzeville, France
}

Correspondence should be addressed to Allal Dakkak; allaldakkak@gmail.com

Received 12 September 2014; Revised 8 March 2015; Accepted 20 March 2015

Academic Editor: Xu-Sheng Zhang

Copyright (C) 2015 Ikhlass El Berbri et al. This is an open access article distributed under the Creative Commons Attribution License, which permits unrestricted use, distribution, and reproduction in any medium, provided the original work is properly cited.

\begin{abstract}
Despite alarming statistics on cystic echinococcosis (CE) in humans and the importance of dog and ruminant populations, no epidemiological investigations have been performed on CE in Sidi Kacem Province (North-West of Morocco). A part of large research project was devoted to determine the status of $\mathrm{CE}$ in ruminants. This paper reports the results of the investigations carried out in the 10 abattoirs of this region, over four successive years (April 2009-March 2013). A total of 1,302 sheep, 652 head of cattle, and 136 goats were postmortem examined and hydatid cysts were collected and examined. The overall CE prevalence of infection was $42.9 \%$ in cattle, $11.0 \%$ in sheep, and $1.5 \%$ in goats. The prevalence shows significant association with age in sheep and cattle; sheep above 3 years and cattle above 5 years are highly infected (64.0\% and $72.2 \%$, resp.). Only liver and lungs are found to be infected. Molecular analyses identified G1, G2, and G3 of E. granulosus sensu stricto in liver and lung samples. Cyst fertility was significantly higher in sheep (54.9\%) than in cattle (50.3\%). These findings suggest that control measures should target not only sheep but also cattle.
\end{abstract}

\section{Introduction}

Cystic echinococcosis (CE) is caused by ingestion of ova of the cestode Echinococcus granulosus (Eg) and then formation of the larval stage in different organs and tissues $[1,2]$. CE is of public health and economic importance not only in areas of endemicity but also in nonendemic countries due to the migration of infected people and livestock exchange which promotes emergence in previously free-disease areas [3]. Unfortunately, numerous reports indicate that CE incidence has increased in various regions of the world [4]. It is endemic to hyperendemic in agricultural countries of Europe, northern, eastern, and southern Africa, southern and northern America, Middle East, and Asia [5-9]. CE represents a substantial burden on the human population. Present estimates suggest that it results in the loss of 1-3 million disabilityadjusted life years per annum. The annual cost of treating cases and economic losses to the livestock industry probably amounts to US\$ 2 billion [10].

$\mathrm{CE}$ represents a serious health problem and has an important impact on the economy and social welfare in Morocco. In 2012, a total of 1,627 human surgical cases of CE (5.2 cases per 100,000 inhabitants) were recorded in the whole country [11]. Surgeries are repeated in $3 \%$ of cases, and a mortality of $3 \%$ was observed. The cost was estimated to be about $1,500 €$ and $3,000 €$ for simple and repeat cases, respectively [12]. Thus, costs would be $2,440,500 €$ for 1,627 simple cases and $129,600 €$ for repeat cases, giving a total cost of $2,570,100 €$. The expenses due to further examinations, reduced quality of life following the surgery, morbidity due to 
undiagnosed CE, and expenses and loss of income in fatal cases were also considered very important [9].

In Morocco, the parasite is transmitted via a synanthropic cycle involving dogs and livestock (sheep, cattle, camels, and Equidae). Review of studies on infection of dogs in several regions [9] showed high prevalence ranging from 22 to $58.8 \%$ and parasite burdens of 1 to 18,940 worms per infected dog. According to Gemmell et al. [13] 8,470 eggs are shed from an average infected dog per day. Thus, the high prevalence of echinococcosis either in rural or in periurban areas and the proportion of stray and free-roaming dogs lead to a very high pollution of the environment with eggs [14]. Therefore, risks of contamination of farm animals and humans are very high.

Relatively numerous epidemiological data are available on CE for several regions of Morocco. Results of studies in five regions [15] showed considerable variations of infection rates among farm animals. The high figures reported were $48.72 \%$ in cattle, $31.65 \%$ in sheep, $2.19 \%$ in goats, $10.87 \%$ in camels, and $17.80 \%$ in horses. These prevalence rates were higher in older animals and reached $84.62 \%$ in cattle more than 5 years of age and $59.15 \%$ and $5.56 \%$ in sheep and goats of more than 3 years of age, respectively $[9,15-18]$. Although records of human surgical cases and the importance of livestock and of canine population suggest a high prevalence of CE, data are lacking for the region of Sidi Kacem Province. This prompted us to include $\mathrm{CE}$ as one of the zoonoses of interest as part of a large collaborative project funded by the EU under FP7, entitled the "Integrated Control of Neglected Zoonoses (ICONZ)" conducted in Sidi Kacem Province. Work on CE included epidemiological investigations on (1) CE infection prevalence in farm ruminants, (2) burden of Eg infection in dogs, (3) socioeconomic impact of the disease, and (4) dynamic of transmission of Eg infection. In this paper, we present the results of the investigations on $\mathrm{CE}$ in ruminants.

\section{Materials and Methods}

2.1. Study Site. The province of Sidi Kacem is located in the North-West of Morocco (Figure 1). It has a total area of about $3094.33 \mathrm{~km}^{2}$ and is divided into 5 municipalities and 24 rural communes [19]. The topography of the province is characterized by the dominance of the plain to the West and the hills to the East. The climate of the region is of a subhumid-Mediterranean type with oceanic influence with an annual rainfall of $600 \mathrm{~mm}$. The cold rainy season extended from October to mid-May, followed by the hot dry period. This province has a strong agricultural character. Livestock represent an integral part of the farming system. The ruminants are estimated at nearly 120,000 head of cattle, 380,000 sheep, and 21,000 goats and these ruminants are extensively reared.

Two dog populations can be identified in Sidi Kacem Province: owned dogs (including sheep dogs) and stray dogs with a population estimated at 20,800 and 2,300 dogs, respectively. Human population is nearly 489,422 inhabitants representing $1.6 \%$ of national population.

2.2. Methodology. This province of Sidi Kacem has a total of 5 small rural slaughterhouses in which only ruminants raised

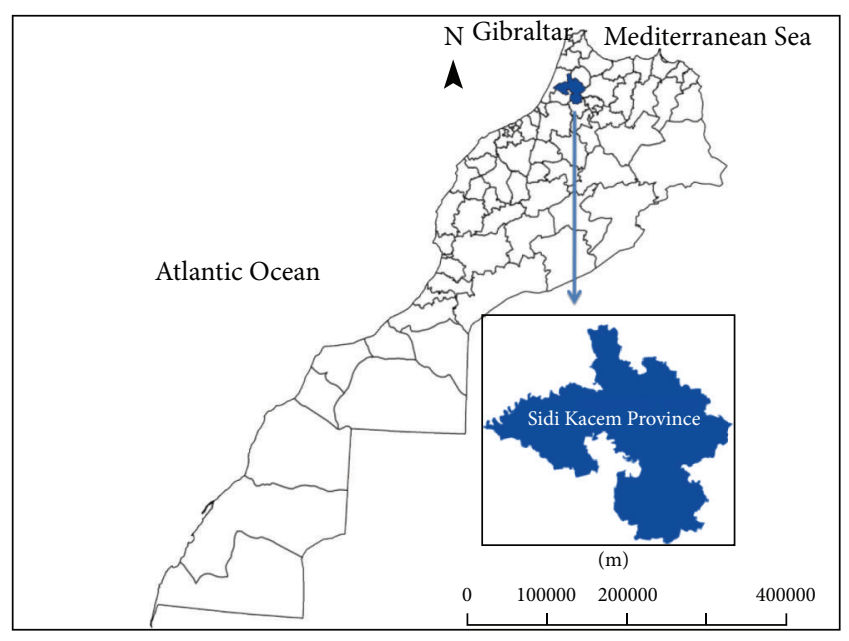

FIgURE 1: Map showing location of Sidi Kacem Province in NorthWest of Morocco.

in the surrounding farms are slaughtered and 5 municipal slaughterhouses in which ruminants raised in the farms located in the 24 rural communes are slaughtered.

A total of 2,090 ruminants (1,302 sheep, 652 head of cattle, and 136 goats) were examined. Postmortem examination was carried out through visual inspection and palpation of visceral organ, especially the lung, liver, kidney, spleen, and heart. All organs or tissues containing hydatid cysts (HC) were collected and all HC found were carefully removed and separately collected for further cyst characterization to assess their status and for genetic strain typing of Eg. Data related to the origin of animals, species, gender, age, cyst distribution, and observation of other diseases were recorded. Sampling took place in four successive years (April 2009-March 2013).

A total of 1,272 $\mathrm{HC}$ were randomly selected from lungs and livers of cattle (913 cysts) and of sheep (359 cysts) and examined to determine their status. Fertility was assessed based on the presence or absence of brood capsules containing protoscolices in hydatid fluid examined microscopically. Infertile cysts were further classified using the classification suggested by Soulsby [20] as sterile (fluid filled cyst without protoscoleces) or calcified. During these investigations the biosecurity rules were strictly observed and all examined biological material and the remains of hydatid cysts were incinerated. To assess genotype, 114 positive samples were randomly selected and DNA was extracted using the iPrep purification instrument (Invitrogen). PCR was carried out for samples with cytochrome c oxydase subunit 1 (coxl) as previously reported [21]. The amplicons were sequenced, and the nucleotide sequences were aligned and compared with sequences available in GenBank. The Eg genotypes were determined using reference sequences for the three genotypes of Eg s.s. concerning coxl [22].

2.3. Data Analysis. Comparison of CE prevalence in different hosts were done using $\chi^{2}$ test. 
TABLE 1: Distribution of hydatid cysts as a function of infected organs.

\begin{tabular}{|c|c|c|c|c|}
\hline \multirow{2}{*}{ Organs } & \multicolumn{2}{|c|}{ Infected cattle } & \multicolumn{2}{|c|}{ Infected sheep } \\
\hline & Number of infected organs & Percent & Number of infected organs & Percent \\
\hline Livers & 84 & 30.0 & 47 & 32.9 \\
\hline Lungs & 86 & 30.7 & 47 & 32.9 \\
\hline Livers and lungs & 110 & 39.3 & 49 & 34.2 \\
\hline Total & 280 & 100 & 143 & 100 \\
\hline
\end{tabular}

TABLE 2: Hydatid cysts fertility in cattle and sheep.

\begin{tabular}{lcccccccc}
\hline & \multicolumn{2}{c}{ Liver } & \multicolumn{2}{c}{ Lung } & \multicolumn{2}{c}{ Liver and lung } & \multicolumn{2}{c}{ Total } \\
& Cattle & Sheep & Cattle & Sheep & Cattle & Sheep & Cattle & Sheep \\
\hline Examined cysts & 123 & 81 & 181 & 94 & 609 & 184 & 913 & 359 \\
Fertile cysts & $51(41.5 \%)$ & $43(53.1 \%)$ & $88(48.6 \%)$ & $45(47.9 \%)$ & $320(52.5 \%)$ & $109(59.2 \%)$ & $459(50.3 \%)$ & $197(54.9 \%)$ \\
Infertile cysts & $72(58.5 \%)$ & $38(46.9 \%)$ & $93(51.4 \%)$ & $49(52.1 \%)$ & $289(47.5 \%)$ & $75(40.8 \%)$ & $454(49.7 \%)$ & $162(45.1 \%)$ \\
\hline
\end{tabular}

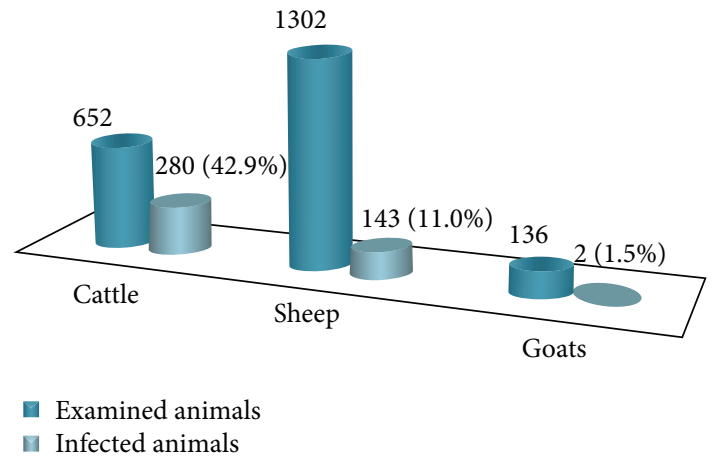

FIGURE 2: Prevalence of cystic echinococcosis in cattle, sheep, and goats.

\section{Results}

3.1. Prevalence of $C E$ in Ruminants. As in other provinces of Morocco, sheep were most commonly slaughtered in the province of Sidi Kacem. In this study, out of 2,090 ruminants (1,302 sheep, 652 head of cattle, and 136 goats) examined in the 10 slaughterhouses of the province, 143 sheep (11.0\%), 280 head of cattle $(42.9 \%)$, and 2 goats $(1.5 \%)$ were found to be infected with one or more hydatid cysts (Figure 2). The magnitude of infection between cattle, sheep, and goats was different $(P<0.001)$.

3.2. Variation of CE Infection Prevalence with Age. The rates of infection increased with age in both species cattle and sheep. The cysts were found in $6.7 \%, 38.9 \%$, and $72.1 \%$ of cattle less than 2 years of age, between 2 and 5 years of age, and more than 5 years of age, for 254, 72, and 326 examined animals, respectively. In sheep, the cysts were found in $3.2 \%$, $12.5 \%$, and $64.0 \%$ of animals less than 1 year of age, between 1 and 3 years of age, and more than 3 years of age, for 966,200 , and 136 , respectively.

3.3. Variation of CE Infection Prevalence with Species and Sex. On the other hand, the comparison of infection rates relative to sex showed that, in both cattle and sheep, females are more frequently infected than males. This difference is more pronounced in cattle than in sheep, namely, $69.1 \%$ versus $9.4 \%$ for 366 and 286 female and male cattle examined, respectively, and $11.2 \%$ versus $9.8 \%$ for 1118 and 184 female and male sheep examined, respectively.

3.4. Distribution and Status of Hydatid Cysts. Hydatid cysts have been encountered in the liver and the lungs only. The difference in the infection rates of hydatidosis between liver and lungs is shown in Table 1. It was observed that coinfection rates of lungs and liver were more frequent in both cattle and sheep $(39.3 \%$ and $34.2 \%$, resp.), while infection rates of lungs only $(30.7 \%$ and $32.9 \%)$ and liver only (30.0\% and $32.9 \%)$ in cattle and in sheep, respectively, were similar.

Only three cystic hydatid cysts were found and collected from the two infected goats. These cysts were all found to be calcified and sterile. The overall percentage of fertile cysts was significantly higher in sheep (54.9\%) than in cattle $(50.3 \%)$ (Table 2).

3.5. Molecular Genotype. Molecular analyses have identified genotypes G1, G2, and G3 of Eg s.s. in $87 \%$ of the selected samples. In the overall samples, we observed a significantly higher number of infections due to the genotype G1 (96\%) than the $\mathrm{G} 3(3 \%)$ and $\mathrm{G} 2(1 \%)$, with a similar rates of infection in cattle and in sheep.

\section{Discussion}

4.1. Prevalence of CE. Principal determinants of Eg livestock infection found in the literature encompassed the level of environmental contamination with parasite eggs and age of the host [23]. Pasture is the main source of nutrition for ruminants in Sidi Kacem Province and is dependent on the favourable terrain and climate: existence of plains, adequate rainfall $(600 \mathrm{~mm})$, and water resources (five of the country's main rivers flow through this region). In this province, El Berbri et al. [24] conducted a survey on knowledge, attitudes, and practices with regard to the presence, transmission 
factors, impact, and control of cystic echinococcosis and reported that pastures are unfortunately accessible to dogs, as confirmed by $34.4 \%$ of respondents. Furthermore, $43.2 \%$ of the population own sheepdogs and $28.7 \%$ of persons report that their dogs have regular access to livestock housing, where they can thus contaminate the animal's feeding and drinking water with Eg eggs. Moreover, according to $7.1 \%$ of respondents, dogs frequent abattoirs on market day, where they invariably become infected with Eg considering the neglectful practices of slaughterhouse workers and inadequate infrastructure of abattoirs. The coexistence of transmission risks in this context, namely, a livestock keeping and dog owning community, promotes the infection of both ruminants and dogs in tandem.

These conditions could explain, at least in part, that CE infection rates in cattle and sheep are slightly higher in Sidi Kacem region than those reported in four other regions of Morocco by Azlaf and Dakkak [15]. These results confirm the CE prevalence variations for the same animal species from region to region in this country. This is similar to the results reported by Torgerson et al. [25] in Kazakhstan. The results of this study show high CE levels of cattle (42.9\%) and sheep $(11.0 \%)$ infection and a reduced infection pressure in goats. Statistical analysis of CE rates on the basis of species shows that a significant difference $(P<0.001)$ exists between cattle, sheep, and goats. These findings are in agreement with the results of previous studies conducted in 5 other regions of Morocco [15-17] (i.e., Rif, Loukkos, Center, Middle Atlas, and South). The prevalence of CE is higher in cattle than in sheep in all of these regions, and for both species the rate of infection is higher in Sidi Kacem region than the national average rate of infection $(22.9 \%$ and $10.5 \%$ in cattle and sheep, resp.) reported by Azlaf and Dakkak [15]. Previous reports in other parts of the world have indicated that the prevalence of CE is high in cattle compared to sheep, including Algeria [2628], Tunisia [29], Ethiopia [30, 31], Saudi Arabia [32], Turkey [33], Greece [34], Iran [35-37], Brazil [38], and Chili [39, 40].

$\mathrm{CE}$ prevalence shows considerable geographical variation. This difference could be associated with different factors which influence the rate of transmission of CE like large dog populations coupled with a high number of home slaughters, risky social activities and attitude towards dogs, control measures put in place, education and economic status of the population, community awareness of the disease, and so forth.

Similarly very low infection rates in goats have been reported in all the regions that have been studied in Morocco [15-17]. Moreover, Tniber [41] and El Hassani [42] reported that in several localities of the Middle Atlas mountains CE rates varied from $0 \%$ to $2 \%$ in goat, whilst in sheep grazing in the same area CE rates ranged from $14.7 \%$ to $76.0 \%$. It has been argued that since goats feed mainly by browsing, rather than grazing, they usually show lower rates of infection [43, 44]. However, high prevalence rates of Cysticercus tenuicollis (Taenia hydatigena larva) infection were reported in goats (72\%) and in sheep (48\%) grazing in the same pastures, while the $\mathrm{CE}$ rates ranged from $0.0 \%$ to $2.4 \%$ in goats and from $14.0 \%$ to $97 \%$ in sheep $[16,41,42,45]$. Other researchers have come to the same conclusion in Tunisia [29], Egypt [46],
Northern Jordan [43], Turkey [43], Iran [35, 44, 47], and Greece [48].

Differences in CE rates between species of animals might be explained mainly as a result of the involvement of different strains of E. granulosus and variations in feeding behaviors of the animals [49].

The genotype G1 of Eg s.s. is the most widespread genotype in the Sidi Kacem Province. We also described for the first time the genotypes G2 and G3 of Eg in Morocco. The genotype G1 is mainly responsible for infection in humans, but genotypes G2 and G3 are known to be infectious as well [50]. In this regard, genetic characterization of Eg isolates collected from sheep, cattle, and goats living in four regions of Morocco [18, 51-53] showed that different hosts from different studied areas harboured genotypes almost identical to the common sheep strain G1 of Eg. On the other hand, Azlaf and Dakkak [15] suggested that this low prevalence of $\mathrm{CE}$ in goats could be attributed to a difference in livestock management system. One of the factors to be considered is that, in Morocco, goats have less contact with dogs than sheep as goats are rarely accompanied by dogs during pasture.

The prevalence of hydatidosis in this study shows significant association with age in sheep and cattle. Cattle above five years of age and sheep above three years of age are highly infected. Data of this study are in agreement with those reported for other regions of Morocco by Azlaf and Dakkak [15], Dakkak and Ouhelli [16], and Pandey et al. [17]. Azlaf and Dakkak [15] showed that the prevalence increased with age approaching an asymptotic prevalence of 1 in the oldest animals. Studies conducted elsewhere also strongly suggest that prevalence is heavily influenced by age, such as in Algeria [26, 27], Tunisia [29], Jordan [43, 54], Iraq [55], Turkey [32], Iran [56, 57], Kazakhstan [25], and Ethiopia [58-64].

The influence of age on rate of infection could be mainly due, on one hand, to increased risk of infection and reinfection because of low immunity and, on the other hand, to the time required for the development of hydatid cysts. It takes 4 to 13 months for a cyst to grow to a few millimeters in diameter [65]. Thus, the inspection techniques used at slaughterhouses cannot detect the presence of all the existing cysts in inspected organs. Smaller microscopic and early cysts can indeed escape inspection. Hence the sensitivity of this method of detection increases in accordance with the age of animals.

In Morocco, cattle are generally slaughtered when they are older than sheep and goats. Under these conditions, higher prevalence in cattle than in sheep and goats could be mainly due to their longer exposure to Eg and/or to lower immunity against the infection. Because prevalence rates are strongly age dependent, reports from abattoirs that may slaughter only young animals, as it is the case in the abattoir of Rabat, the capital of Morocco, substantially underrepresent the true situation of CE in farm animals [16].

Comparison of infection rates relative to sex showed that, in both cattle and sheep, females are significantly more frequently infected than males. This difference is more pronounced in cattle than in sheep, namely, $69.1 \%$ versus $9.4 \%$ and $11.2 \%$ versus $9.8 \%$, respectively. These results are in agreement with those reported in different regions of Morocco 
[15-17]. This is in agreement also with the finding by Daryani et al. [66] and Taghavil et al. [57] in Iran, Khanmohammadi et al. [67] in Pakistan, Abunna et al. [58] in Ethiopia, and Lahmar et al. [29] in Tunisia. The higher infection rates in female sheep and cattle compared to males can be due to the older ages of slaughtered females than males. In practice, female cattle, sheep, and goats are usually maintained for longer periods than males to give offspring several times before being slaughtered. In contrast, most male cattle, sheep, and goats are slaughtered at young ages of six months to less than two years. As we discussed above, in younger animals, hydatid cysts either have not developed to a detectable size or are too small and easy to miss.

With regard to the distribution of hydatid cysts in different organs of infected cattle and sheep, hydatid cysts have been encountered in the liver and the lungs only, and both in sheep and cattle the distribution of cysts showed little significant variation between the two organs in both animal species $\left(\chi^{2}=0.267, P>0.05\right)$. This is in agreement with results found by Azlaf and Dakkak [15] who reported that lungs and liver were the most commonly affected organs by hydatid cysts in 618 head of cattle and 2948 sheep examined in five different regions of Morocco, while hydatid cysts were detected only in one heart, one spleen, and one peritoneum in cattle and in one spleen in sheep. On the other hand, the majority of infected cattle (39.3\%) and sheep (34.2\%) had hydatid cysts in both liver and lungs. Concomitant infection of both liver and lung is slightly higher in cattle (39.3\%) than in sheep (34.2\%). These findings are in fundamental agreement with the literature, which states that hydatid cysts are most commonly found in the liver and lungs of ungulates $[20,28,32,68-71]$. However, our results are at odds with the findings from studies conducted in Libya [72], Iran [55, 63, 73], Jordan [74, 75], and Tunisia [29], where researchers reported higher prevalence in the liver than in the lungs. They are also at odds with findings from studies conducted in Ethiopia [64, 76-80], Pakistan [81, 82], Bangladesh [83], Iran $[57,84]$, and Nigeria [85], where researchers reported higher prevalence in the lungs than in the liver.

These preferential localizations can be explained by the migration of hatched oncosphere, which when leaving the intestine attains the liver, the right heart, the lungs, the left heart, and finally other organs and tissues. Following this migratory pathway, the larvae meet two organs first, the liver and the lungs, which are the first large capillary fields encountered by the blood borne oncosphere and where they are subjected to the filtering action sequentially before any other peripheral organ is invaded [5]. In other cases the development of hydatid cysts occurs occasionally in other organs such as the heart, kidney, spleen, peritoneum, and other tissues when oncospheres have escaped into the general systematic circulation [69].

Fertility rate of the hydatid cyst is of great importance in epidemiological studies, not only for the possibility of fertile cysts to disseminate the disease but also to define the probable function of each intermediate host species as a potential host in the spread of the infection. Only three cysts were detected in the two infected goats. These cysts were all found calcified and sterile. This corroborates the reported results in different regions of Morocco showing that the fertility rate of hydatid cysts of goat origin varies from $0 \%$ to $2.5 \%[15,16,52]$. These results are in agreement with those reported in Algeria [27], Iraq [55], and Ethiopia [86]. Because it has been shown that different hosts from different studied areas of Morocco harboured genotypes almost similar to the common sheep strain G1 $[18,52,53]$, these findings would suggest that the sheep strain G1 is not adapted to goats. On the other hand, sterile cysts of goats or cattle may be attributed to the degenerative atrophy caused by body reaction against such cysts leading to caseation and calcification followed by degenerations [87].

With regard to fertility of cysts found in sheep and cattle, the overall percentage of fertile cysts was significantly higher in sheep $(54.9 \%)$ than in cattle $(50.3 \%)$. This is close to previous estimates reported for different regions of Morocco [15-17] and corroborates with the reported results of neighboring countries: Algeria [27], Tunisia [29], Libya $[88,89]$, and Mauritania [90]. Similar results were also reported in other countries including Egypt [46], Turkey [33, 91], Iran [26], Italy [92], and Ethiopia [93]. This variation could be attributed to strain differences in traits such as host preference, development rate, infectivity, and pathogenesis.

In sheep, the frequency of occurrence of fertile cysts is higher in the liver than in the lungs $(53.1 \%$ versus $47.9 \%$, resp.). The results obtained in sheep are in agreement with those already reported by several authors in Morocco [15-17] and with those reported in Tunisia [29], Libya [94], Jordan [54], Soudan [95], Iraq [96], Iran [32, 97], and Ethiopia [31]. However, Anwar et al. [82], Costa-Jamett et al., [49], Scala et al. [98], and Getachew et al. [86] have reported that the fertility of pulmonary cysts in sheep was higher than that of hepatic cysts.

In cattle, and as in studies conducted in other regions of Morocco [15-17], the percentage of fertile cysts was found to be higher in the lungs than in the liver $(48.6 \%$ versus $41.5 \%$, resp.). Similar results were reported in Tunisia [29], Egypt [46], Iran [97, 99], Ethiopia [31, 59, 76, 77], and Pakistan [82].

The importance of sheep and cattle as intermediate hosts of Eg in several regions of Morocco has been demonstrated by other authors [15-17].

The results of this study would suggest that because of a higher rate of infection, cattle play the leading role in the maintenance of $\mathrm{CE}$ in the region and would contradict the well-known notion that "cystic echinococcosis is principally maintained in a dog-sheep-dog cycle." However, in the province of Sidi Kacem as in other regions studied to date in Morocco and in other countries of North Africa in general, although the rate of infection is lower in sheep than in cattle, a number of factors indicate that sheep are the main source of infection to dogs. Indeed, (1) the sheep population is about 3 times greater than that of cattle, (2) sheep are most commonly slaughtered in all North Africa countries, (3) each sheep flock is followed by one or two dogs which are often fed on offal and carcasses left to vagrant dogs or wild carnivores, (4) dogs may be incorrectly fed with potentially infected viscera during clandestine slaughtering and home slaughtering at different occasions, such as weddings and religious feasts, and (5) fertility of hydatid cysts of sheep origin is almost 
always higher than that of hydatid cysts of cattle origin. Finally, in addition to its basic interest, the present study confirms the role of cattle in leading transmission to dogs and, consequently, to humans and suggests that control measures should target not only sheep but also cattle.

ICONZ project includes the development of a control strategy using the results of research on infection in ruminants, infection in $\operatorname{dog}[100]$, and risk factors of infection in humans, dogs, and ruminants [24]. This strategy was developed and communicated to the Moroccan authorities concerned with the subject. The project also includes the field evaluation of this strategy and this evaluation is now underway.

\section{Disclaimer}

The contents of this paper are the sole responsibility of the authors and do not necessarily reflect the views of the European Commission.

\section{Conflict of Interests}

The authors declare that there is no conflict of interests regarding the publication of this paper.

\section{Acknowledgments}

This research has received funding from the European Union's Seventh Framework Program (FP7/2007-2013) under Grant Agreement no. 221948, ICONZ (Integrated Control of Neglected Zoonoses).

\section{References}

[1] D. P. McManus, W. Zhang, J. Li, and P. B. Bartley, "Echinococcosis," The Lancet, vol. 362, no. 9392, pp. 1295-1304, 2003.

[2] J. Eckert and P. Deplazes, "Biological, epidemiological, and clinical aspects of echinococcosis, a zoonosis of increasing concern," Clinical Microbiology Reviews, vol. 17, no. 1, pp. 107135,2004

[3] W. Mamuti, H. Yamasaki, Y. Sako et al., "Usefulness of hydatid cyst fluid of Echinococcus granulosus developed in mice with secondary infection for serodiagnosis of cystic Echinococcosis in humans," Clinical and Diagnostic Laboratory Immunology, vol. 9, no. 3, pp. 573-576, 2002.

[4] J. Eckert, F. J. Conraths, and K. Tackmann, "Echinococcosis: an emerging or re-emerging zoonosis?” International Journal for Parasitology, vol. 30, no. 12-13, pp. 1283-1294, 2000.

[5] R. M. Matossian, M. D. Rickard, and J. D. Smyth, "Hydatidosis: a global problem of increasing importance," Bulletin of the World Health Organization, vol. 55, no. 4, pp. 499-507, 1977.

[6] H. Wen and W.-G. Yang, "Public health importance of cystic echinococcosis in China," Acta Tropica, vol. 67, no. 1-2, pp. 133$145,1997$.

[7] P. R. Torgerson and C. M. Budke, "Echinococcosis: an international public health challenge," Research in Veterinary Science, vol. 74, no. 3, pp. 191-202, 2003.

[8] C. M. Budke, P. Deplazes, and P. R. Torgerson, "Global socioeconomic impact of cystic echinococcosis," Emerging Infectious Diseases, vol. 12, no. 2, pp. 296-303, 2006.
[9] A. Dakkak, "Echinococcosis/hydatidosis: a severe threat in Mediterranean countries," Veterinary Parasitology, vol. 174, no. 1-2, pp. 2-11, 2010.

[10] P. R. Torgerson and P. Craig, "Updated global burden of cystic and alveolar echinococcosis," Report of the WHO Informal Working Group on Cystic and Alveolar Echinococcosis Surveillance, Prevention and Control, with the Participation of the Food and Agriculture Organization of the United Nations and the World Organisation for Animal Health, Department of Control of Neglected Tropical Diseases WHO, Geneva, Switzerland, 2011.

[11] Ministry of Health Morocco, Direction de l'Epidémiologie et de la Lutte Contre les Maladies. Service des Maladies Parasitaires, Ministry of Health Morocco, Rabat, Morocco, 2012.

[12] M. Lyagoubi, S. Mouline, A. El Mesnaoui, A. A. Aziz, and M. K. Soussi, "Surgical procedures used in Morocco for removal of hydatid cysts," in Compendium on Cystic Echinococcosis in Africa and in Middle Eastern Countries with Special Reference to Morocco, F. L. Anderson, H. Ouhelli, and M. Kachani, Eds., pp. 186-193, Brigham Young University, Provo, Utah, USA, 1997.

[13] M. A. Gemmell, M. G. Roberts, T. C. Beard, and J. R. Lawson, "Quantitative epidemiology and transmission dynamics with special reference to Echinococcus granulosus," in WHO/OIE Manual on Echinococcosis in Humans and Animals: A Public Health Problem of Global Concern, J. Eckert, M. A. Gemmell, F. F. X. Meslin, and Z. S. Pawlowski, Eds., pp. 143-156, OIE, Paris, France, 2001.

[14] A. Dakkak, "Le chien et la contamination de l'environnement par les oncospheres d'Echinococcus granulosus: cas de 4 régions du Maroc," in Congrès de la Société Française de Parasitologie, Maisons-Alfort, France, December 2003.

[15] R. Azlaf and A. Dakkak, "Epidemiological study of the cystic echinococcosis in Morocco," Veterinary Parasitology, vol. 137, no. 1-2, pp. 83-93, 2006.

[16] A. Dakkak and H. Ouhelli, "Epidémiologie de l'echinococcoses/ hydatidose au Maroc," in Proceedings of the 12th Conference of the World Association for the Advancement of Veterinary Parasitology, Berlin, Germany, August 1989.

[17] V. S. Pandey, H. Ouhelli, and M. Ouchtou, "Hydatidosis in sheep, goats and dromedaries in Morocco," Annals of Tropical Medicine and Parasitology, vol. 80, no. 5, pp. 525-530, 1986.

[18] R. Azlaf, Echinococcosis/hydatidosis in Morocco: epidemiology, modeling, Echinococcus granulosus genotyping and molecular analysis [Ph.D. thesis], Hassan II Institute of Agronomy and Veterinary Medicine, Rabat, Morocco, 2007.

[19] Office national de Sécurité sanitaire Alimentaire (ONSSA), Monographie de la Province de Sidi Kacem. Service Vétérinaire de la Province de Sidi Kacem, Office national de Sécurité sanitaire Alimentaire (ONSSA), Agadir, Morocco, 2010.

[20] E. J. L. Soulsby, Helminths, Arthropods and Protozoa of Domesticated Animals, Lea \& Febiger, 7th edition, 1982.

[21] G. Umhang, C. Richomme, J.-M. Boucher, V. Hormaz, and F. Boué, "Prevalence survey and first molecular characterization of Echinococcus granulosus in France," Parasitology Research, vol. 112, no. 4, pp. 1809-1812, 2013.

[22] J. Bowles, D. Blair, and D. P. McManus, "Genetic variants within the genus Echinococcus identified by mitochondrial DNA sequencing," Molecular and Biochemical Parasitology, vol. 54, no. 2, pp. 165-173, 1992.

[23] B. Otero-Abad and P. R. Torgerson, "A Systematic Review of the Epidemiology of Echinococcosis in Domestic and Wild 
Animals," PLoS Neglected Tropical Diseases, vol. 7, no. 6, Article ID e2249, 2013.

[24] I. El Berbri, A. F. Petavy, O. F. Fihri et al., "Knowledge, attitudes and practices with regards to the presence, transmission factors, impact, and control of cystic echinococcosis in Sidi Kacem Province, Morocco," PLoS Neglected Tropical Diseases. Submitted.

[25] P. R. Torgerson, K. K. Burtisurnov, B. S. Shaikenov, A. T. Rysmukhambetova, A. M. Abdybekova, and A. E. Ussenbayev, "Modelling the transmission dynamics of Echinococcus granulosus in sheep and cattle in Kazakhstan," Veterinary Parasitology, vol. 114, no. 2, pp. 143-153, 2003.

[26] K. Hamrat, Y. Achour, G. Yacin, and V. Cozma, "Epidemiological study of hydatidosis in the steppe regions of Djelfa, Algeria," Scientia Parasitologica, vol. 12, pp. 177-183, 2011.

[27] F. B. Kouidri, F. Benchaib Khoudja, A. Boulkaboul, and M. Selles, "Prevalence, fertility and viability of cystic echinococcosis in sheep and cattle of Algeria," Bulgarian Journal of Veterinary Medicine, vol. 15, no. 3, pp. 191-197, 2012.

[28] K. Bardonnet, M. C. Benchikh-Elfegoun, J. M. Bart et al., "Cystic echinococcosis in Algeria: cattle act as reservoirs of a sheep strain and may contribute to human contamination," Veterinary Parasitology, vol. 116, no. 1, pp. 35-44, 2003.

[29] S. Lahmar, M. Trifi, S. ben Naceur et al., "Cystic echinococcosis in slaughtered domestic ruminants from Tunisia," Journal of Helminthology, vol. 87, no. 3, pp. 318-325, 2013.

[30] A. Fromsa and Y. Jobre, "Infection prevalence of hydatidosis (Echinococcus granulosus, Batsch, 1786) in domestic animals in Ethiopia: a synthesis report of previous surveys," Ethiopian Veterinary Journal, vol. 15, no. 2, pp. 11-33, 2011.

[31] H. Degefu and T. Damet, "Hydatidosis of cattle and sheep, its economic importance and Echinococcus granulosus among stray dogs in South Wollo, Ethiopia," Ethiopian Veterinary Journal, vol. 17, no. 2, pp. 101-119, 2013.

[32] M. M. Ibrahim, "Study of cystic echinococcosis in slaughtered animals in Al Baha region, Saudi Arabia: interaction between some biotic and abiotic factors," Acta Tropica, vol. 113, no. 1, pp. 26-33, 2010.

[33] M. U. Esatgil and E. Tüzer, "Prevalence of hydatidosis in slaughtered animals in Thrace, Turkey," Turkish Society for Parasitology, vol. 31, no. 1, pp. 41-45, 2007.

[34] P. Economides and G. Christofi, "Evaluation of control programmes for echinococcosis/hydatidosis in Cyprus," Revue Scientifique et Technique, vol. 19, no. 3, pp. 784-792, 2000.

[35] D. Mehrabani, A. Oryan, and S. M. Sadjjadi, "Prevalence of Echinococcus granulosus infection in stray dogs and herbivores in Shiraz, Iran," Veterinary Parasitology, vol. 86, no. 3, pp. 217220,1999

[36] A. Dalimi, G. Motamedi, M. Hosseini et al., "Echinococcosis/hydatidosis in western Iran," Veterinary Parasitology, vol. 105, no. 2, pp. 161-171, 2002.

[37] M. R. Nejad, S. Jahani-Sherafat, K. Cheraghipour, E. N. Mojarad, N. Taghipour, and M. R. Zali, "Hydatic cyst prevalence in slaughtered animals. A neglected health problem," Journal of Paramedical Sciences, vol. 3, no. 3, pp. 25-29, 2012.

[38] C. S. Nunes, "Status of hydatidosis in Brazil," in Proceedings of the Scientific Working Group on the Advances in the Prevention, Control and Treatment of Hydatidosis, A. Ruiz, P. M. Schantz, and P. Arambulo III, Eds., pp. 148-159, Pan American Health Organization, Washington, DC, USA, 1995.
[39] P. Arambulo III, "Public health importance of cystic echinococcosis in Latin America," Acta Tropica, vol. 67, no. 1-2, pp. 113-124, 1997.

[40] W. Apt, C. Pérez, E. Galdamez et al., "Echinococcosis/ hydatidosis in region VII of Chile: diagnosis and educational intervention," Revista Panamericana de Salud Publica, vol. 7, no. 1, pp. 8-16, 2000.

[41] M. Tniber, Epidémiolgie des parasitoses ovines au Moyen Atlas et aux Rhamnas [Ph.D. thesis], Institut Agronomique et Vétérinaire Hassan II, Rabat, Maroc, 1998.

[42] M. E. A. El Hassani, Epidémiologie des maladies parasitaires de la chèvre au Moyen Atlas (Ifrane) [Ph.D. thesis], Institut Agronomique et Vétérinaire Hassan II, Rabat, Morocco, 1992.

[43] P. R. Torgerson, D. H. Williams, and M. N. Abo-Shehada, "Modelling the prevalence of Echinococcus and Taenia species in small ruminants of different ages in northern Jordan," Veterinary Parasitology, vol. 79, no. 1, pp. 35-51, 1998.

[44] M. Arbabi and H. Hooshyar, "Survey of echinococcosis and hydatidosis in Kashan region, Central Iran," Iranian Journal of Public Health, vol. 35, no. 1, pp. 75-81, 2006.

[45] A. A. Taleb, Epidémiologie des parasitoses ovines au Moyen Atlas (Timahdit-El Hajeb) et au Rhamnas [Ph.D. thesis], Institut Agronomique et Vétérinaire Hassan II, Rabat, Morocco, 1987.

[46] F. M. Haridy, B. B. Ibrahim, A. M. Elshazly et al., "Hydatidosis in Egyptian slaughtered animals in the years 2000-2005," Journal of the Egyptian Society of Parasitology, vol. 6, pp. 1087-1100, 2006.

[47] A. Oryan, S. Goorgipour, M. Moazeni, and S. Shirian, "Abattoir prevalence, organ distribution, public health and economic importance of major metacestodes in sheep, goats and cattle in Fars, Southern Iran," Tropical Biomedicine, vol. 29, no. 3, pp. 349-359, 2012.

[48] A. Varcasia, S. Canu, A. Kogkos et al., "Molecular characterization of Echinococcus granulosus in sheep and goats of Peloponnesus, Greece," Parasitology Research, vol. 101, no. 4, pp. 1135-1139, 2007.

[49] G. Costa-Jamett, S. Cleaveland, A. A. Cunningham, B. M. C. Bronsvoort, N. Ahmadi, and A. Dalimi, "Characterization of Echinococcus granulosus isolates from human, sheep and camel in Iran," Infection, Genetics and Evolution, vol. 6, no. 2, pp. 8590, 2006.

[50] J. Eckert and R. C. A. Thompson, "Intraspecific variation of Echinococcus granulosus and related species with emphasis on their infectivity to humans," Acta Tropica, vol. 64, no. 1-2, pp. 19-34, 1997.

[51] A. Dakkak, "Echinococcosis/hydatidosis in Noth Africa: 'geographical distribution of species and strains and prevalence in man and animals," in WHO Guidlines for Diagnosis, Surveillance and Control of Echinococcosis/Hydatidosis, Veterinary Public Health and Communicable Diseases Division, Ed., WHO, Geneva, Switzerland, 1992.

[52] B. Najimi, Echinococcus granulosus: morphologie etc polymorphisme enzymatique de populations parasites de l'homme et des animaux d'élevage [Thèse 3ème cycle], Faculté des Sciences Rabat, Rabat, Morocco, 1995.

[53] A. Dakkak, A. B. Najimi, and T. Ben Azzou, "Echnococcus granulosus: genetic homogeneity of isolates from sheep, cattle, and humans in Morocco," in Proceedings of the 26th World Veterinary Congress, Lyon, France, September 1999.

[54] S. Kamhawi, N. Hijjawi, A. Abu-Gazaleh, and M. Abbass, "Prevalence of hydatid cysts in livestock from five regions of 
Jordan," Annals of Tropical Medicine and Parasitology, vol. 89, no. 6, pp. 621-629, 1995.

[55] M. T. Jarjees and H. S. Al-Bakri, "Incidence of hydatidosis in slaughtered livestock at Mosul, Iraq," Iraqi Journal of Veterinary Sciences, vol. 26, no. 1, pp. 21-25, 2012.

[56] P. A. Cabrera, P. Irabedra, D. Orlando, L. Rista, G. Haran, and G. Vinals, "An abattoir survey of liver and lung hydatidosis in North-West Iran," Journal of Novel Applied Sciences, vol. 2, pp. 710-712, 2013.

[57] M. Taghavil, M. Mirzaei, and M. Fartashvand, "Abattoir Survey of Liver and Lung hydatidosis in Northwest Iran," Journal of Novel Applied Sciences, vol. 2, pp. 710-712, 2013.

[58] F. Abunna, S. Fentaye, B. Megersa, and A. Regassa, "Prevalence of bovine hydatidosis in Kombolcha ELFORA abattoir, NorthEastern Ethiopia," Open Journal of Animal Sciences, vol. 2, no. 4, pp. 281-286, 2012.

[59] N. Kebede, A. Mitiku, and G. Tilahun, "Hydatidosis of slaughtered animals in Bahir Dar Abattoir, North-western Ethiopia," Tropical Animal Health and Production, vol. 41, no. 1, pp. 43-50, 2009.

[60] A. Endrias, T. Yechale, and M. Assefa, "Bovine hydatidosis in Ambo municipal abattoir, West Shoa, Ethiopia," Ethiopian Veterinary Journal, vol. 14, pp. 1-14, 2010.

[61] F. Regassa, A. Molla, and J. Bekele, "Study on the prevalence of cystic hydatidosis and its economic significance in cattle slaughtered at Hawassa Municipal abattoir, Ethiopia," Tropical Animal Health and Production, vol. 42, no. 5, pp. 977-984, 2010.

[62] M. Genet, G. Tadesse, B. Basaznew, and C. Mersha, "Pathological conditions causing organ and carcass condemnation and their financial losses in cattle slaughtered in Gondar, Northwest-Ethiopia," African Journal of Basic \& Applied Sciences, vol. 4, pp. 200-208, 2012.

[63] M. Miheret, M. Biruk, T. Habtamu, and K. Ashwani, "Bovine hydatidosis in Eastern part of Ethiopia," Momona Ethiopian Journal of Science, vol. 5, no. 1, pp. 107-114, 2013.

[64] D. Endalew and I. Nuraddis, "Prevalence and economic importance of hydatidosis in cattle slaughtered at North Gondar Elfora abattoir," European Journal of Applied Sciences, vol. 5, pp. 29-35, 2013.

[65] J. D. McConnell and R. J. Green, "The control of hydatid diseases in Tasmania," Australian Veterinary Journal, vol. 55, no. 3, pp. 140-145, 1979.

[66] A. Daryani, R. Alaei, R. Arab, M. Sharif, M. H. Dehghan, and H. Ziaei, "The prevalence, intensity and viability of hydatid cysts in slaughtered animals in the Ardabil province of Northwest Iran," Journal of Helminthology, vol. 81, no. 1, pp. 13-17, 2007.

[67] M. Khanmohammadi, S. Gayem Maghami, and M. Zakaria Zadeh, "The prevalence of hydatidosis by sex, season and location in slaughtered buffaloes at the Tabriz abattoir in 20062007," The Internet Journal of Veterinary Medicine, vol. 4, no. 2, 2007.

[68] M. D. Angus, Veterinary Helminthology, William Heinemann Medical Books, London, UK, 2nd edition, 1978.

[69] G. M. Urquhart, J. Duncan, L. Armour, J. Dunn, and J. A. M. Jenning, Veterinary Parasitology, Blackwell Science, Oxford, UK, 2nd edition, 1996.

[70] Y. Jobre, F. Lobago, R. Tiruneh, G. Abebe, and P. Dorchies, "Hydatidosis in three selected regions in Ethiopia: an assessment trial on its prevalence, economic and public health importance," Revue de Médecine Véterinaire, vol. 147, no. 11, pp. 797-804, 1996.
[71] N. Kebede, "A retrospective survey of bovine hydatidosis in three abattoirs of Amhara National Regional State, Northwestern Ethiopia," Tropical Animal Health and Production, vol. 42, no. 3, pp. 323-325, 2010.

[72] F. Banda, K. S. Nalubamba, J. B. Muma, M. Munyeme, and H. M. Munang'andu, "A cross-sectional study investigating cystic hydatidosis in slaughtered Cattle of Western Province in Zambia," ISRN Parasitology, vol. 2013, Article ID 468163, 9 pages, 2013.

[73] D. Yitbarek, T. Mulugeta, and B. Mihreteab, "Prevalence of hydatidosis in sheep slaughtered at Abergelle export abattoir, Mekelle, Northern Ethiopia," Global Veterinaria, vol. 9, no. 4, pp. 490-496, 2012.

[74] F. M. Al-Yaman, L. Assaf, N. Hailat, and S. K. Abdel-Hafez, "Prevalence of hydatidosis in slaughtered animals from North Jordan," Annals of Tropical Medicine and Parasitology, vol. 79, no. 5, pp. 501-506, 1985.

[75] M. N. Abo-Shehada, "Some observations on hydatidosis in Jordan," Journal of Helminthology, vol. 67, no. 3, pp. 248-252, 1993.

[76] G. Berhe, "Abattoir survey on cattle hydatidosis in Tigray region of Ethiopia," Tropical Animal Health and Production, vol. 41, no. 7, pp. 1347-1352, 2009.

[77] A. Melaku, B. Lukas, and B. Bogale, "Cyst viability, organ distribution and financial losses due to hydatidosis in cattle slaughtered at Dessie Municipal abattoir, North-Eastern Ethiopia," Veterinary World, vol. 5, no. 4, pp. 213-218, 2012.

[78] D. Terefe, K. Kibrusfaw, D. Beyene, and A. Wondimu, "Prevalence and financial loss estimation of hydatidosis of cattle slaughtered at Addis Ababa abattoirs enterprise," Journal of Veterinary Medicine and Animal Health, vol. 4, no. 3, pp. 42-47, 2012.

[79] B. Jemere, K. Wosenyelesh, S. Shishun, and S. Desie, "Prevalence and financial loss estimation of cystic echinococcosis in cattle slaughtered at Mizan Tefri and Teppi Municipal abattoir, SouthWestern Ethiopia," European Journal of Applied Sciences, vol. 5, pp. 12-18, 2013.

[80] A. Alemu, N. Nigatu, T. Tariku, T. Getachew, and K. Tesfu, "Occurrences and financial significance of bovine cystic echinococcosis in Southern Wollo, Northeastern Ethiopia," Journal of Veterinary Medicine and Animal Health, vol. 5, pp. 51-56, 2013.

[81] A. Anwar, A. U. Haq, S. A. Gill, and A. H. Chaudhry, "Prevalence and fertility ratio of hydatid cyst in slaughtered sheep and goats at Faisalabad," Pakistan Veterinary Journal, vol. 13, pp. 7981, 1993.

[82] A. Anwar, H. Shamim, H. Rana, M. Khan, and A. Qudoos, "Hydatidosis: prevalence and biometrical studies in cattle (Bob indicub)," Pakistan Journal of Agricultural Sciences, vol. 37, pp. $1-2,2000$.

[83] M. K. Islam, S. C. Basak, S. Majumder, S. A. Sarder, A. W. M. S. Islam, and M. M. H. Mondal, "Cystic echinococcosis in domestic ruminants in Cox's Bazar of Bangladesh," Pakistan Journal of Scientific and Industrial Research, vol. 46, no. 4, pp. 251-254, 2003.

[84] N. A. Ahmadi and M. Meshkehkar, "An abattoir-based study on the prevalence and economic losses due to cystic echinococcosis in slaughtered herbivores in Ahwaz, South-Western Iran," Journal of helminthology, vol. 85, no. 1, pp. 33-39, 2011.

[85] S. I. B. Cadmus and H. K. Adesokan, "Causes and implications of bovine organs/offal condemnations in some abattoirs in 
Western Nigeria," Tropical Animal Health and Production, vol. 41, no. 7, pp. 1455-1463, 2009.

[86] D. Getachew, G. Almaw, and T. Getachew, "Occurrence and fertility rates of hydatid cysts in sheep and goats slaughtered at Modjo Luna Export Slaughter House, Ethiopia," Ethiopian Veterinary Journal, vol. 16, no. 1, pp. 83-91, 2012.

[87] R. L. Rausch, "Echinococcus granulosus: biology and ecology," in Compendium on Cystic Echinococcosis in Africa and Middle Eastern Countries with Reference to Morocco, p. 345, Brigham Young University, Provo, Utah, USA, 2007.

[88] M. M. Ibrahim and A. M. Gusbi, "Cystic echinococcosis in North Africa (excluding Morocco): veterinary aspects," in Compendium on Cystic Echinococcosis in Africa and in Middle Eastern Countries with Special Reference to Morocco, F. L. Anderson, H. Ouhelli, and M. Kachani, Eds., pp. 207-222, Brigham Young University, Provo, Utah, USA, 1997.

[89] A. H. Khan, A. A. El-Buni, and M. Y. Ali, "Fertility of the cysts of Echinococcus granulosus in domestic herbivores from Benghazi, Libya and the reactivity of antigens produced from them," Annals of Tropical Medicine and Parasitology, vol. 95, no. 4, pp. 337-342, 2001.

[90] C. B. O. A. Salem, F. Schneegans, J. Y. Chollet, and M. H. Jemli, "Epidemiological studies on echinococcosis and characterization of human and livestock hydatid cysts in Mauritania," Iranian Journal of Parasitology, vol. 6, no. 1, pp. 49-57, 2011.

[91] K. Yildiz and S. Gurcan, "Prevalence of hydatidosis and fertility of hydatid cysts in sheep in Kirikkale, Turkey," Acta Veterinaria Hungarica, vol. 51, no. 2, pp. 181-187, 2003.

[92] G. Garippa, "Updates on cystic echinococcosis in Italy," Parassitologia, vol. 48, no. 1-2, pp. 57-59, 2006.

[93] L. Fikre, Echinococcosis/hydatidosis in Konso (southern Ethiopia) an assessment trial of its prevalence, economic and public health importance [Doctorate of Veterinary Medicine thesis], Faculty of Veterinary Medicine, Addis Ababa University, Debre Zeit, Ethiopia, 1994.

[94] A. M. Gusbi, M. A. Q. Awan, and W. N. Beesley, "Echinococcis in Libya. II. Prevalence of hydatidosis Echinococcus granulosus in sheep," Annals of Tropical Medicine and Parasitology, vol. 81, no. 1, pp. 35-41, 1987.

[95] S. A. Mohamadin and A. E. Abdelgadir, "Study on hydatid cyst infection in slaughterhouses in Khartoum state, Sudan," Archives of Applied Science Research, vol. 3, pp. 18-23, 2011.

[96] I. Saeed, C. Kapel, L. A. Saida, L. Willingham, and P. Nansen, "Epidemiology of Echinococcus granulosus in Arbil province, northern Iraq, 1990-1998," Journal of Helminthology, vol. 74, no. 1, pp. 83-88, 2000.

[97] A. Daryani, M. Sharif, A. Amouei, and M. Nasrolahei, "Fertility and viability rates of hydatid cysts in slaughtered animals in the Mazandaran Province, Northern Iran," Tropical Animal Health and Production, vol. 41, no. 8, pp. 1701-1705, 2009.

[98] A. Scala, G. Garippa, A. Varcasia, V. M. Tranquillo, and C. Genchi, "Cystic echinococcosis in slaughtered sheep in Sardinia (Italy)," Veterinary Parasitology, vol. 135, no. 1, pp. 33-38, 2006.

[99] H. Hamidieh and A. A. Deylamiasl, "Fertility rate of hydatid cyst in sheep and cattle slaughtered at zanjan abattoir in 1998," Scientific Journal of Hamadan University of Medical Sciences and Health Services, vol. 7, pp. 10-14, 2000.

[100] I. El Berbri, A. F. Petavy, M. Bouslikhane, O. F. Fihri, F. Boué, and A. Dakkak, "Epidemiological investigations on cystic echinococcosis in North-West (Sidi Kacem Province) Morocco: infection in dogs," PLoS Neglected Tropical Diseases. Submitted. 


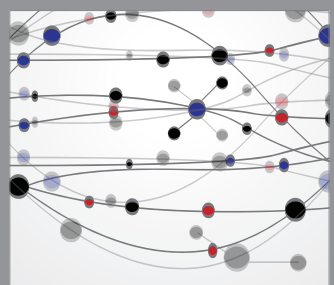

The Scientific World Journal
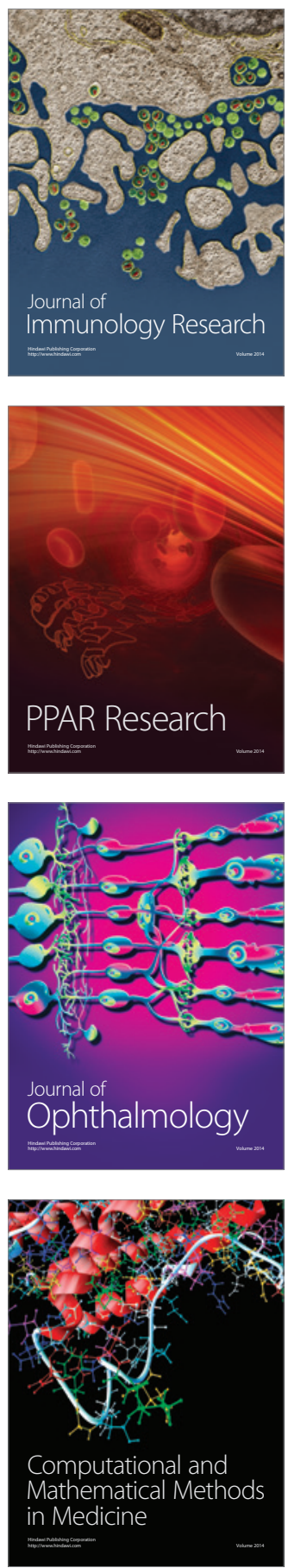

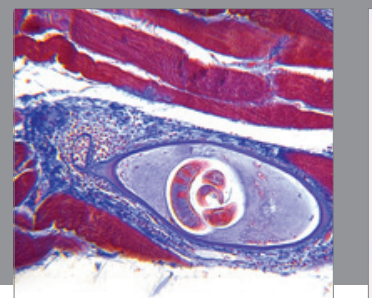

Gastroenterology

Research and Practice
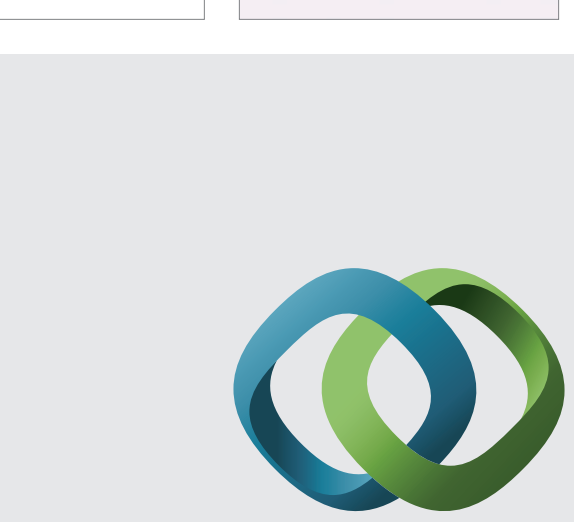

\section{Hindawi}

Submit your manuscripts at

http://www.hindawi.com
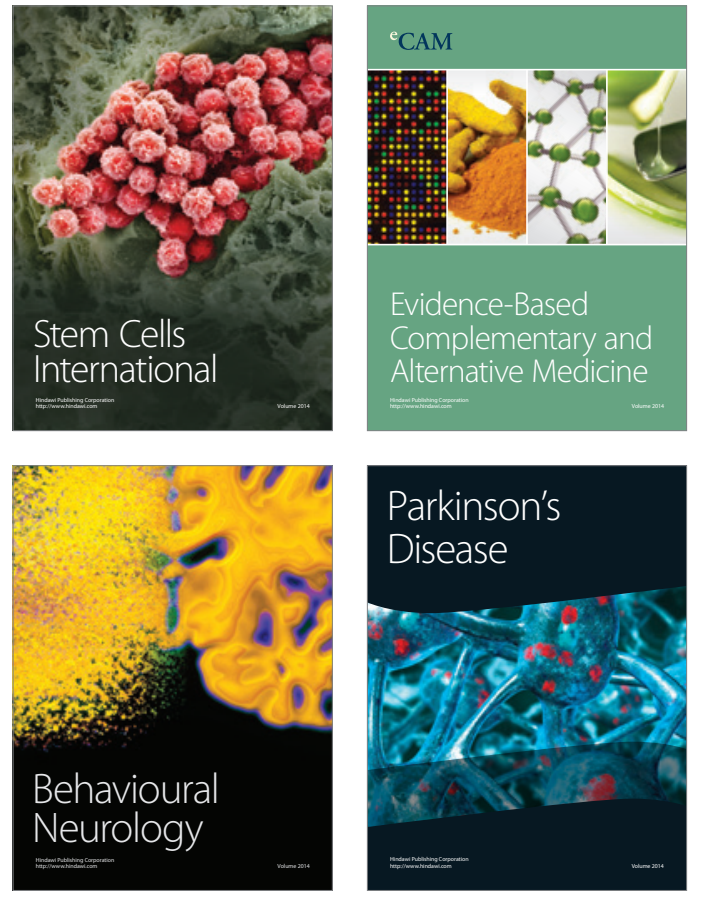
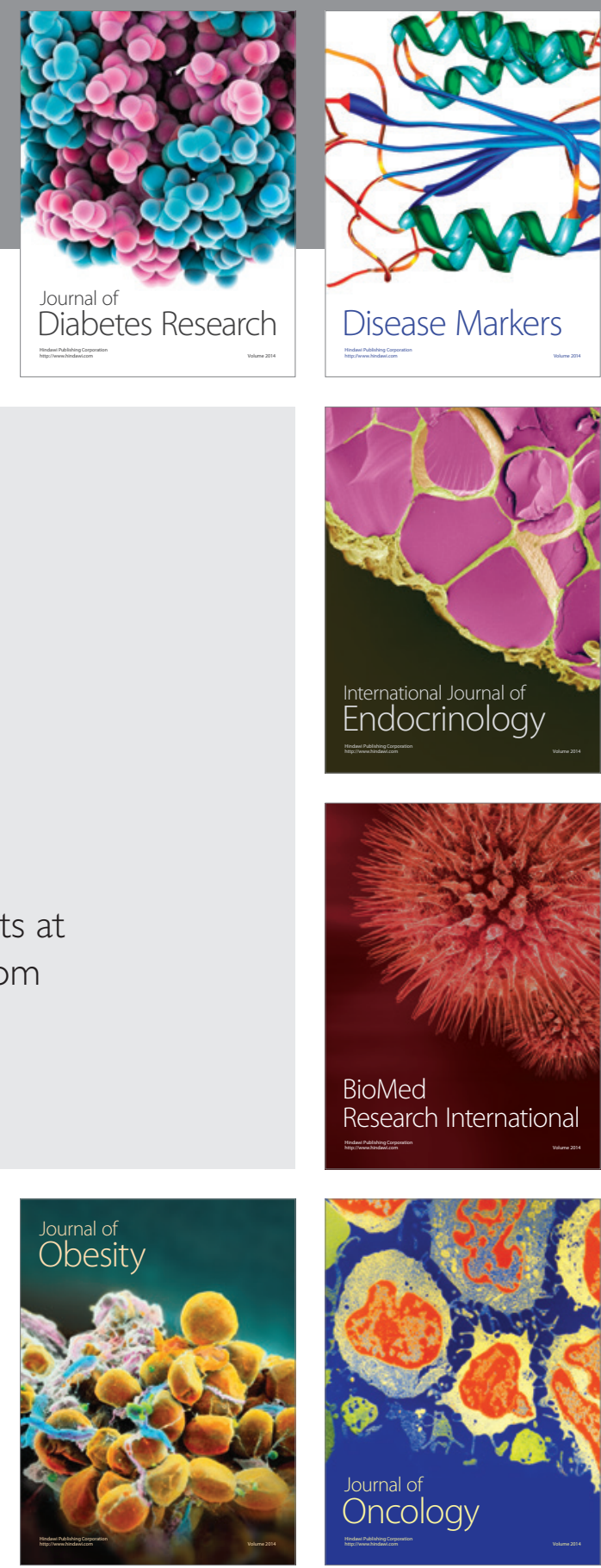

Disease Markers
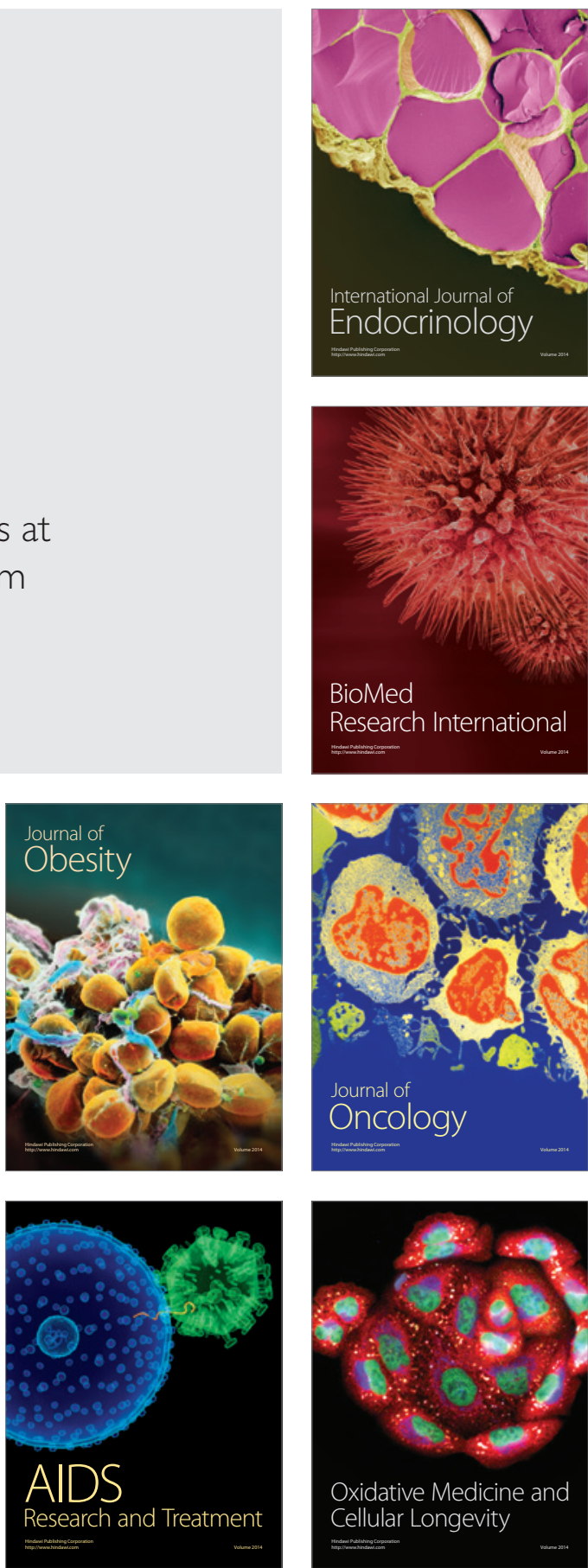